\title{
Absence of an association of human polyomavirus and papillomavirus infection with lung cancer in China: a nested case- control study
}

Danny V. Colombara ${ }^{1,2,7^{*}}$, Lisa E. Manhart', Joseph J. Carter', Stephen E. Hawes ${ }^{1}$, Noel S. Weiss ${ }^{1,2}$, James P. Hughes ${ }^{2,3}$, You-Lin Qiao ${ }^{4}$, Philip R. Taylor ${ }^{5}$, Jennifer S. Smith ${ }^{6}$ and Denise A. Galloway ${ }^{2}$

\begin{abstract}
Background: Studies of human polyomavirus (HPyV) infection and lung cancer are limited and those regarding the association of human papillomavirus (HPV) infection and lung cancer have produced inconsistent results.

Methods: We conducted a nested case-control study to assess the association between incident lung cancer of various histologies and evidence of prior infection with HPyVs and HPVs. We selected serum from 183 cases and 217 frequency matched controls from the Yunnan Tin Miner's Cohort study, which was designed to identify biomarkers for early detection of lung cancer. Using multiplex liquid bead microarray (LBMA) antibody assays, we tested for antibodies to the VP1 structural protein and small T antigen (ST-Ag) of Merkel cell, Kl, and WU HPyVs. We also tested for antibodies against HPV L1 structural proteins (high-risk types 16, 18, 31, 33, 52, and 58 and low-risk types 6 and 11) and E6 and E7 oncoproteins (high risk types 16 and 18). Measures of antibody reactivity were log transformed and analyzed using logistic regression.
\end{abstract}

Results: We found no association between KIV, WUV, and MCV antibody levels and incident lung cancer (P-corrected for multiple comparisons $>0.10$ for all trend tests). We also found no association with HPV-16, 18, 31, 33, 52, and 58 seropositivity (P-corrected for multiple comparisons $>0.05$ for all).

Conclusions: Future studies of infectious etiologies of lung cancer should look beyond HPyVs and HPVs as candidate infectious agents.

Keywords: Lung cancer, Human polyomavirus, KI polyomavirus, WU polyomavirus, Merkel cell polyomavirus, Human papillomavirus

\section{Background}

In China, lung cancer is the most commonly diagnosed cancer in males, the second most common in females, and the leading cause of cancer related death for both sexes by a substantial margin [1]. The burden of lung cancer in China is also rising, with disability-adjusted life years per 100,000 increasing by more than $50 \%$ between 1990 (552, $95 \%$ confidence interval (CI): 458-782) and

\footnotetext{
* Correspondence: dvc2@uw.edu

${ }^{1}$ Department of Epidemiology, School of Public Health, University of Washington, Seattle, WA, USA

${ }^{2}$ Fred Hutchinson Cancer Research Center, Seattle, WA, USA

Full list of author information is available at the end of the article
}

2010 (843, 95 \% CI: 590-990) [2]. Smoking, air pollution (industrial emissions, cooking exhaust, second hand smoke, and residential radon), and genetics are established lung cancer risk factors that explain the majority, but not all, of this burden of disease [3, 4]. However, seven viruses are known to be causally associated with human cancers [5], with their carcinogenic potential often realized only in the presence of environmental mutagens and other cofactors [6]. Due to the lung's propensity for infection, it is possible that some lung cancers may have an infectious etiology.

The 2008 discovery of Merkel cell carcinoma's association with Merkel cell polyomavirus (MCV) provided 
the first evidence that human polyomaviruses (HPyVs) may have carcinogenic potential in humans [7]. Since MCV and other polyomaviruses such as KI (KIV) and WU (WUV), can infect the lower respiratory tract [8-10], their association with lung cancer has been previously examined, but results have been inconclusive. Small MCV studies have reported prevalence estimates of up to nearly $40 \%$ for MCV DNA in lung tumors [11-14]. Less consistency has been observed in studies of the association of KIV and WUV with lung cancer. A small European study reported that KIV DNA was found in $45 \%(9 / 20)$ of lung tumors but only $5 \%(1 / 20)$ of control tissue [15]. However, these results were not confirmed by additional studies which examined KIV and or WUV in lung tumors [16-18]. Despite prior infection with human polyomaviruses being nearly ubiquitous [19], prior studies report that high levels of MCV antibodies were associated with Merkel cell carcinoma [20]. However, in the only other seroepidemiologic study, antibodies to MCV, KIV and WUV were not associated with lung cancer in a US population [21]. Nevertheless, given the influence of host genetics on susceptibility to cancer, these associations may differ in different populations.

The human papillomavirus (HPV) family has undisputed carcinogenic potential, with HPV infection playing a causal role in nearly all cervical cancers, a large proportion of other anogenital cancers, and more than a quarter of oropharyngeal cancers [22, 23]. In addition, HPV infections are involved in the development of respiratory papillomas [24], which occasionally exhibit malignant transformation [25]. Based on this evidence, there have been numerous studies of the association between HPV infection and lung cancer. In 2009, a meta-analysis and a systematic review independently concluded that the evidence for an association remained inconclusive, but stronger associations were observed in East Asia [26, 27]. More recently, a 2015 metaanalysis concluded that HPV infection is associated with increased risk for lung cancer [28]. However, only nine studies were included in the analysis, with all of the studies having tested lung tissue for current evidence of infection as opposed to longitudinally collected sera that could be used to assess prior infection. In addition, the degree of heterogeneity reported was not inconsequential and the metaanalysis used only crude data, which was unadjusted for potential confounders such as age and smoking status [29]. Finally, as the authors noted, there were some indications of publication bias. Therefore, HPV's association with lung cancer remains an open question.

\section{Methods}

\section{Study population}

Between 1992 and 1998, 9,295 eligible Yunnan Tin Corporation (YTC) employees were enrolled in a cohort study of early markers of lung cancer in Yunnan, China
[30]. Participants were current or retired YTC workers, at least 40 years of age, with a history of at least 10 years underground and/or smelting experience, and no previous malignancies (except non-melanoma skin cancer).

\section{Data and specimen collection}

Participants completed an interviewer-administered questionnaire regarding demographics, lung cancer symptoms, eating habits, and medical, smoking and occupational history. They also received at least one yearly screening exam consisting of sputum cytology, chest $\mathrm{x}$ rays, and a physical exam provided by the YTC General Worker's Hospital. All positive, and $2 \%$ of negative, cytology slides were re-read for diagnosis and adequacy of preparation by YTC and a Johns Hopkins University pathologist. Two radiologists read each chest $\mathrm{x}$-ray, with differences resolved by a third reader. In addition, yearly sputum specimens and a one-time sample of urine, $10 \mathrm{~mL}$ of whole blood, and toenail clippings were collected and preserved for future studies. Plasma was separated from whole blood and stored at $-70{ }^{\circ} \mathrm{C}$. Follow-up activities ceased on December 31, 2001.

Participants provided signed informed consent and the institutional review boards (IRBs) of the National Cancer Institute (NCI) and the YTC approved the original cohort study. The IRBs of the University of Washington, the Fred Hutchinson Cancer Research Center, the Cancer Institute of the Chinese Academy of Medical Sciences, and the $\mathrm{NCI}$ approved this analysis.

\section{Case definition}

Cases $(n=183)$ are defined as individuals with incident lung cancer of any histology (small cell carcinoma, squamous cell carcinoma, adenocarcinoma, and other). Incident lung cancer was determined in one of four ways: 1) detection during annual screenings utilizing chest $\mathrm{x}$-rays and sputum cytology, followed-up by confirmatory diagnosis at the YTC General Worker's Hospital, 2) presentation to and diagnosis at the YTC General Worker's Hospital among those with symptoms, 3) searching the YTC cancer registry system which contains data from local hospitals, or 4) searching hospital based vital records for deceased cohort members and identifying the cause of death. Controls $(n=217)$ were frequency matched on age and the number of freeze-thaw cycles. Since only two of the lung cancer cases occurred in women, this study was limited to men.

\section{Exposure assessment}

We used a Bio-Plex 200 instrument (Bio-rad Laboratories) to perform multiplex liquid bead microarray (LBMA) antibody assays following standard procedures [20, 31, 32]. We obtained and analyzed the median fluorescent intensity (MFI), a surrogate for antibody titer. We 
tested sera for antibodies against the VP1 structural protein and small T antigen (ST-Ag) oncoprotein of Merkel cell, KI, and WU HPyVs. In addition, we tested for antibodies against HPV L1 structural proteins (high-risk types $16,18,31,33,52$, and 58 and low-risk types 6 and 11 ) and E6 and E7 oncoproteins (high risk types 16 and 18 only). Glutathione S-transferase (GST) fusion proteins and BK virus antigens served as negative and positive controls, respectively. All fusion proteins had an eleven amino acid epitope "Tag" added to the Cterminus to assess expression levels [20]. Between $89.3 \%$ and $95 \%$ of sera were seropositive for BK VP1, depending on whether we used a threshold of 400 or 200 MFI, respectively. Sera were incubated at a final concentration of 1:100.

\section{Statistical methods}

Since HPyV infection was expected to be common, we compared the range of MFI between cases and controls rather than dichotomizing specimens as seropositive or seronegative. We assessed the association between $\mathrm{HPyV}$ infection and lung cancer using MFI quartiles as the independent variable in logistic regression analyses. In contrast, we dichotomized HPV MFI in order to increase comparability of our HPV analysis with prior LBMA based studies. We defined HPV seropositivity as $>400$ MFI (>5.99 log transformed MFI (lnMFI) $[31,33$, $34]$ in our primary analysis and $>200$ MFI $(>5.30 \operatorname{lnMFI})$ $[34,35]$ in a sensitivity analysis. We also assessed the association between each viral antibody and incident lung cancer using logistic regression trend tests with continuous $\operatorname{lnMFI}$ as the independent variable. MFI were log transformed and all logistic regression analyses were adjusted for matching variables.

Since a total of 18 antibodies were assessed for an association with incident lung cancer, we created exposure categories to account for multiple comparisons. We created three categories of HPyV exposure: MCV (VP1 and ST-Ag), KIV (VP1 and ST-Ag), and WUV (VP1 and STAg). Similarly, four categories of HPV exposure were created: low-risk HPV (6, 11 L1), HPV-16 (E6, E7, and L1), HPV-18 (E6, E7, and L1), and other high-risk HPV (31, 33, 52, $58 \mathrm{~L} 1)$. We corrected our $P$-values for multiple comparisons by using permutation tests with 10,000 permutations to establish a null distribution of the most significant exposure across the multiple exposures in each exposure category [36]. The proportion of the time that the empirical test statistic was less than or equal to the test statistic calculated using permuted datasets was defined as the corrected $P$-value.

We assessed effect modification by smoking history (linear pack-years), radon exposure (Working Level Month (WLM)), and arsenic exposure (Index of Arsenic Exposure Months (IAEM)) using likelihood ratio tests. If radon, and arsenic exposure were not effect modifiers, they were considered potential confounders, along with smoking history and a family history of lung cancer (yes, no). If inclusion of a candidate confounder in the regression models changed the odds ratio (OR) of interest by $<10 \%$, that candidate was not included in the final model.

In exploratory analyses, boxplots were used to assess the association of antigen-specific MFI with individual histologic types.

All analyses used two-sided statistical tests and were performed with Stata/IC 13.1 (StataCorp LP, College Station, TX).

\section{Results}

The age distribution was similar between cases and controls, but the controls were better educated $(\mathrm{P}=0.04)$ (Table 1). Cases were more likely to have ever smoked tobacco (96.7 \% vs. $90.8 \%, \mathrm{P}=0.02)$, but had similar overall levels of tobacco, arsenic, and radon exposure. Nearly two-fifths of the cases had squamous cell carcinoma (39.3\%), $16.9 \%$ had adenocarcinoma, $13.7 \%$ had small cell carcinoma, $10.4 \%$ had a mixed histology, and $19.7 \%$ had other histologies or the histology was not obtained.

The distribution of antigen specific antibodies was similar among lung cancer cases and controls (Table 2). The maximum difference in the mean lnMFI between cases and controls was 0.3 for HPV 16 E7 and HPV $11 \mathrm{~L} 1$ antibodies.

In multivariate analyses there was little evidence for confounding so the models were adjusted only for matching variables in the main analysis. The results of the regression analysis comparing the highest to the lowest quartile of MCV antibodies with respect to incident lung cancer found no appreciable association for either VP1 $(\mathrm{aOR}=0.90,95 \%$ CI: 0.37-2.17) or ST-Ag $(\mathrm{aOR}=$ 0.85, 95 \% CI: 0.48-1.48) (Table 3). Compared to men with the lowest levels of KIV antibodies, those with the highest quartile of VP1 (aOR $=1.44,95 \%$ CI: 0.82-2.52) and ST-Ag (aOR = 1.13, 95 \% CI: 0.65-1.98) did not face a significantly increased risk of lung cancer. Those with the highest quartile of WUV VP1 $(\mathrm{aOR}=1.47,95 \%$ CI: $0.84-2.58)$ and WUV ST-Ag $(\mathrm{aOR}=1.02,95 \% \mathrm{CI}$ : 0.58-1.78) antibodies also showed no evidence of increased risk. Linear trend tests of these associations confirmed the lack of association $(\mathrm{P}>0.10$ for all HPyV antibodies). A sensitivity analysis that included adjustment for education and ever smoking, both of which were associated with case status, did not differ substantially from the main analysis $(<10 \%$ change in the odds ratio) (Additional file 1: Table S1).

HPV 16 L1 (aOR = 1.17, 95 \% CI: 0.43-3.21) seropositivity was not associated with increased lung cancer risk 
Table 1 Characteristics of selected lung cancer cases and frequency matched controls: Yunnan, China 1992-1998

\begin{tabular}{|c|c|c|c|c|c|}
\hline \multirow[t]{2}{*}{ Characteristic } & \multicolumn{2}{|c|}{ Cases $(n=183)$} & \multicolumn{2}{|c|}{ Controls $(n=217)$} & \multirow[t]{2}{*}{$P$} \\
\hline & $n$ & $\%$ & $n$ & $\%$ & \\
\hline Age & & & & & 0.914 \\
\hline $40-49$ & 3 & (1.6) & 4 & $(1.8)$ & \\
\hline $50-59$ & 58 & $(31.7)$ & 71 & $(32.7)$ & \\
\hline $60-69$ & 104 & $(56.8)$ & 125 & $(57.6)$ & \\
\hline $70-79$ & 18 & (9.8) & 17 & (7.8) & \\
\hline Education level $^{a}$ & & & & & 0.043 \\
\hline None & 82 & $(44.8)$ & 87 & $(40.1)$ & \\
\hline K-5 & 89 & $(48.6)$ & 98 & $(45.2)$ & \\
\hline $6-8$ & 9 & $(4.9)$ & 15 & (6.9) & \\
\hline $9-12$ & 2 & $(1.1)$ & 5 & $(2.3)$ & \\
\hline College & 1 & $(0.5)$ & 12 & $(5.5)$ & \\
\hline Body Mass Index (BMI) $\left(\mathrm{kg} / \mathrm{m}^{2}\right)$ & & & & & 0.230 \\
\hline Underweight $(<18.5)$ & 18 & (9.8) & 36 & $(16.6)$ & \\
\hline Normal (18.5-24.99) & 138 & $(75.4)$ & 150 & $(69.1)$ & \\
\hline Overweight (25-29.99) & 24 & $(13.1)$ & 29 & $(13.4)$ & \\
\hline Obese $(\geq 30)$ & 3 & (1.6) & 2 & $(0.9)$ & \\
\hline Ever smoked tobacco ${ }^{b}$ & 177 & $(96.7)$ & 197 & $(90.8)$ & 0.016 \\
\hline Pack-years, median (IQR $\left.{ }^{\mathrm{C}}\right)$ & 36 & $(24-54)$ & 32 & $(19-49)$ & 0.132 \\
\hline Arsenic ${ }^{d}$, median $\left(\mid Q^{C}{ }^{c}\right)$ & 10745 & $(6695-15347)$ & 9420 & $(4888-16802)$ & 0.057 \\
\hline Radon ${ }^{\mathrm{e}}$, median $\left(\mathrm{IQR}{ }^{\mathrm{C}}\right)$ & 498 & $(277-783)$ & 417 & $(171-681)$ & 0.132 \\
\hline Family history of lung cancer ${ }^{f}$ & 3 & (1.6) & 6 & $(2.8)$ & 0.449 \\
\hline Any prior lung disease ${ }^{g}$ & 88 & $(48.1)$ & 98 & $(45.2)$ & 0.559 \\
\hline Asthma or hay fever & 25 & $(13.7)$ & 24 & $(11.1)$ & 0.429 \\
\hline Tuberculosis (self-report) & 8 & $(4.4)$ & 14 & $(6.5)$ & 0.363 \\
\hline Chronic bronchitis & 72 & $(39.3)$ & 78 & $(35.9)$ & 0.484 \\
\hline Silicosis & 20 & $(10.9)$ & 18 & $(8.3)$ & 0.371 \\
\hline Lung cancer histology & & & & & NA \\
\hline Squamous cell carcinoma & 72 & (39.3) & 0 & $(-)$ & \\
\hline Adenocarcinoma & 31 & $(16.9)$ & 0 & $(-)$ & \\
\hline Small cell carcinoma & 25 & $(13.7)$ & 0 & $(-)$ & \\
\hline Mixed & 19 & $(10.4)$ & 0 & $(-)$ & \\
\hline Other & 2 & $(1.1)$ & 0 & $(-)$ & \\
\hline Not obtained & 34 & $(18.6)$ & 0 & $(-)$ & \\
\hline Lung cancer site & & & & & NA \\
\hline Main bronchus & 15 & $(8.2)$ & 0 & $(-)$ & \\
\hline Upper lobe bronchus or lung & 76 & $(41.5)$ & 0 & $(-)$ & \\
\hline
\end{tabular}


Table 1 Characteristics of selected lung cancer cases and frequency matched controls: Yunnan, China 1992-1998 (Continued)

\begin{tabular}{|c|c|c|c|c|}
\hline Middle lobe lung & 19 & $(10.4)$ & 0 & $(-)$ \\
\hline Lower lobe bronchus or lung & 60 & (32.8) & 0 & $(-)$ \\
\hline Other parts of bronchus or lung & 3 & (1.6) & 0 & $(-)$ \\
\hline Bronchus and lung NOS & 10 & (5.5) & 0 & $(-)$ \\
\hline
\end{tabular}

(Table 4). HPV 18 L1 seropositivity also showed no evidence of increased risk ( $\mathrm{aOR}=0.29,95 \% \mathrm{CI}$ : 0.03-2.66).

Table 2 The distribution of antigen specific antibodies ${ }^{a}$ among lung cancer cases and controls

\begin{tabular}{|c|c|c|c|c|c|}
\hline \multirow[b]{3}{*}{ Antibody } & \multicolumn{2}{|l|}{ Cases } & \multicolumn{2}{|c|}{ Controls } & \multirow[b]{3}{*}{ Difference } \\
\hline & \multicolumn{2}{|c|}{$(n=183)$} & \multicolumn{2}{|c|}{$(n=217)$} & \\
\hline & Mean & SD & Mean & SD & \\
\hline \multicolumn{6}{|l|}{ HPyV } \\
\hline$M C V^{b} V P 1^{c}$ & 8.4 & 2.5 & 8.4 & 2.5 & 0 \\
\hline MCV ST-Ag ${ }^{d}$ & 1.1 & 1.8 & 1.1 & 2 & 0 \\
\hline $\mathrm{KIV}^{\mathrm{e}} \mathrm{VP1}{ }^{\mathrm{c}}$ & 9 & 1.9 & 8.9 & 1.5 & 0.1 \\
\hline KIV ST-Ag ${ }^{d}$ & 1.9 & 1.9 & 1.9 & 1.9 & 0 \\
\hline$W U V^{f} V P 1^{c}$ & 9.2 & 1 & 9.1 & .8 & 0.1 \\
\hline WUV ST-Ag ${ }^{d}$ & 1.7 & 1.8 & 1.6 & 1.7 & 0.1 \\
\hline \multicolumn{6}{|l|}{ HPV 916} \\
\hline E6 & .4 & 1.2 & .2 & 1 & 0.2 \\
\hline E7 & 1.7 & 2.6 & 1.4 & 2.3 & 0.3 \\
\hline L1 & 1.3 & 2.1 & 1.1 & 1.9 & 0.2 \\
\hline
\end{tabular}

HPV 18

$\begin{array}{llllll}\text { E6 } & 1.6 & 2 & 1.5 & 1.9 & 0.1 \\ \text { E7 } & .6 & 1.6 & .5 & 1.4 & 0.1 \\ \text { L1 } & 2.1 & 2 & 2.1 & 1.9 & 0\end{array}$

Other high-risk HPV ${ }^{9}$

\begin{tabular}{clllll}
$31 \mathrm{~L} 1$ & 2.6 & 2.3 & 2.6 & 2.5 & 0 \\
$33 \mathrm{~L} 1$ & 1.8 & 2 & 1.7 & 1.9 & 0.1 \\
$52 \mathrm{~L} 1$ & 5 & 2 & 5 & 1.9 & 0 \\
$58 \mathrm{~L} 1$ & 3.5 & 2.4 & 3.4 & 2.3 & 0.1 \\
Low-risk HPV & & & & & \\
$6 \mathrm{~L} 1$ & 5.1 & 2.7 & 4.9 & 2.6 & 0.2 \\
$11 \mathrm{~L} 1$ & 4 & 2.4 & 3.7 & 2.4 & 0.3 \\
\hline
\end{tabular}

${ }^{a}$ Measured in units of natural log transformed median fluorescence intensity (InMFI). The "Mean" is the arithmetic mean, "SD" is the standard deviation, and "Difference" is equal to the mean of the cases minus the mean of the controls

${ }^{\mathrm{b}} \mathrm{MCV}=$ Merkel cell polyomavirus

VP1 = the primary structural protein of human polyomaviruses

d $\mathrm{ST}-\mathrm{Ag}=$ the small $\mathrm{T}$-antigen of human polyomaviruses

${ }^{\mathrm{e}} \mathrm{KIV}=\mathrm{KI}$ polyomavirus

${ }^{\mathrm{f}} \mathrm{WUV}=\mathrm{WU}$ polyomavirus

${ }^{\mathrm{g}} \mathrm{HPV}=$ Human papillomavirus
Seropositivity to other high-risk HPV types and low-risk HPV types also showed no relationship with lung cancer incidence (adjusted $\mathrm{P}>0.05$ for all). The aOR for linear trend tests of HPV lnMFI in association with incident lung cancer ranged from 1.00 (95\% CI: 0.90-1.11) for HPV 52 L1 to 1.17 (95 \% CI: 0.97-1.43) for HPV16 E6. The sensitivity analysis using a threshold of 5.30 lnMFI also showed no evidence of an association ( $\mathrm{P}>0.05$ for all) (Additional file 2: Table S2). Additional sensitivity analyses that included adjustment for education and ever smoking did not differ substantially from the main analyses with threshold at $5.99 \ln$ MFI or the alternative threshold of $5.30 \operatorname{lnMFI}$ ( $<10 \%$ change in the odds ratio) (Additional file 3: Table S3 and Additional file 4: Table S4 respectively).

Exploratory boxplots showed no evidence of an association between antigen-specific antibodies and any specific lung cancer histology (Figs. 1, 2 and 3).

\section{Discussion}

In this seroepidemiologic study of the association of HPyV and HPV and incident lung cancer in Asia, multivariable regression analyses of pooled histology types and visual exploration of boxplots stratified by histology type demonstrated no evidence of an association between the levels of these viral antibodies and lung cancer. These results are consistent with our previous seroepidemiologic study in an American population, which also found no association between HPyV antibody levels and lung cancer [21].

Only one small European study using nucleic acid amplification testing (NAAT) to detect viral DNA found a strong association between lung cancer of undescribed histology and KIV [15]. Subsequent NAAT based studies of KIV and small cell carcinoma and large cell neuroendocrine carcinoma [16], adenocarcinoma [17], and small cell neuroendocrine carcinoma [18] all failed to confirm these positive findings. Among the studies of MCV and WUV in association with lung cancer, the majority did 
Table 3 Association between antigen specific human polyomavirus (HPyV) antibody levels and incident lung cancer, adjusted for matching variables

\begin{tabular}{|c|c|c|c|c|c|}
\hline \multirow[b]{2}{*}{ Antibody quartile } & \multicolumn{3}{|l|}{ Mean } & \multicolumn{2}{|l|}{ Trend Test $^{d}$} \\
\hline & $\overline{\operatorname{lnMFI}}{ }^{a}$ & $\mathrm{aOR}\left(95 \% \mathrm{Cl}^{\mathrm{b}}\right)$ & $p^{c}$ & $\overline{O R}\left(95 \% \mathrm{Cl}^{\mathrm{b}}\right)$ & $p^{c}$ \\
\hline $\mathrm{MCV}^{e} V P 1^{f}$ & & & & $1.00(0.92-1.09)$ & 0.951 \\
\hline 1 & 5.03 & Referent & & & \\
\hline 2 & 8.50 & $0.67(0.38-1.17)$ & 0.163 & & \\
\hline 3 & 9.74 & $0.80(0.49-1.31)$ & 0.372 & & \\
\hline 4 & 12.57 & $0.90(0.37-2.17)$ & 0.810 & & \\
\hline MCV ST-Ag ${ }^{g}$ & & & & $0.97(0.88-1.08)$ & 0.623 \\
\hline 1 & 0.02 & Referent & & & \\
\hline 2 & 0.05 & $1.01(0.58-1.76)$ & 0.985 & & \\
\hline 3 & 0.25 & $0.70(0.40-1.22)$ & 0.209 & & \\
\hline 4 & 4.12 & $0.85(0.48-1.48)$ & 0.553 & & \\
\hline $\mathrm{KIV}^{\mathrm{h}} \mathrm{VP} 1^{\mathrm{g}}$ & & & & $1.04(0.92-1.17)$ & 0.532 \\
\hline 1 & 6.92 & Referent & & & \\
\hline 2 & 8.65 & $1.07(0.61-1.88)$ & 0.821 & & \\
\hline 3 & 9.32 & $1.64(0.94-2.89)$ & 0.089 & & \\
\hline 4 & 10.81 & $1.44(0.82-2.52)$ & 0.206 & & \\
\hline $\mathrm{KIV}^{\mathrm{h}} \mathrm{ST}-\mathrm{Ag}^{\mathrm{g}}$ & & & & $0.99(0.90-1.10)$ & 0.878 \\
\hline 1 & 0.02 & Referent & & & \\
\hline 2 & 0.22 & $1.00(0.58-1.75)$ & 0.991 & & \\
\hline 3 & 3.00 & $0.72(0.41-1.27)$ & 0.260 & & \\
\hline 4 & 4.43 & $1.13(0.65-1.98)$ & 0.652 & & \\
\hline WUV' VP1 ${ }^{g}$ & & & & $1.20(0.96-1.51)$ & 0.112 \\
\hline 1 & 8.16 & Referent & & & \\
\hline 2 & 8.86 & $1.34(0.77-2.36)$ & 0.305 & & \\
\hline 3 & 9.34 & $1.15(0.65-2.01)$ & 0.643 & & \\
\hline 4 & 10.13 & $1.47(0.84-2.58)$ & 0.182 & & \\
\hline WUV' ST-Ag ${ }^{g}$ & & & & $1.02(0.91-1.14)$ & 0.734 \\
\hline 1 & 0.02 & Referent & & & \\
\hline 2 & 0.07 & $0.95(0.55-1.67)$ & 0.871 & & \\
\hline 3 & 2.40 & $0.83(0.47-1.45)$ & 0.522 & & \\
\hline 4 & 4.04 & $1.02(0.58-1.78)$ & 0.951 & & \\
\hline
\end{tabular}

${ }^{\mathrm{a}} \mathrm{InMFI}=$ natural log transformed median fluorescence intensity

${ }^{b}$ Nominal (uncorrected) $95 \%$ confidence intervals

c $P$-values are corrected for multiple comparisons using permutation tests

${ }^{d}$ The trend tests estimate the odds ratio for a one unit increase in natural log transformed MFI, adjusted for matched variables

${ }^{\mathrm{e}} \mathrm{MCV}=$ Merkel cell polyomavirus

${ }^{f}$ VP1 $=$ the primary structural protein of human polyomaviruses

g ST-Ag = the small T-antigen of human polyomaviruses

${ }^{\mathrm{h}} \mathrm{KIV}=\mathrm{KI}$ polyomavirus

${ }^{i} \mathrm{WUV}=\mathrm{WU}$ polyomavirus

not have a true comparison group, which limits the ability to determine possible associations $[11,13,14,16-$ 18]. One study that assessed tumors along with adjacent benign tissue reported finding MCV DNA in 5 of 30 cases as compared to 2 of 21 controls [12], which provides a non-statistically significant OR of 1.9 .

In contrast to meta-analyses which reported potential associations between lung cancer and HPV in East Asia
$[27,28,37]$, we found no evidence of an association with seropositivity to eight different HPV types. To date, more than $100 \mathrm{HPV} /$ lung cancer association studies have been conducted [37] and wide ranging differences in reported associations among East Asian countries have been noted [26]. Since our sero-assay was less sensitive than NAATs, it remains unclear whether previous positive associations were due to contamination [38, 39] 
Table 4 Association between human papillomavirus (HPV) seropositivity ${ }^{a}$ and incident lung cancer, adjusted for matching variables

\begin{tabular}{|c|c|c|c|c|c|c|}
\hline \multirow[t]{2}{*}{ Antibody } & \multirow{2}{*}{$\begin{array}{l}\text { Cases }(n=200) \\
\%\end{array}$} & \multirow{2}{*}{$\begin{array}{l}\text { Controls }(n=200) \\
\%\end{array}$} & \multirow[b]{2}{*}{ OR $\left(95 \% \mathrm{Cl}^{\mathrm{C}}\right)$} & \multirow[b]{2}{*}{$p^{d}$} & \multicolumn{2}{|l|}{ Trend Test ${ }^{b}$} \\
\hline & & & & & OR $\left(95 \% \mathrm{Cl}^{\mathrm{C}}\right)$ & $p^{d}$ \\
\hline \multicolumn{7}{|l|}{ HPV 16} \\
\hline E6 & 0.5 & 1.4 & $0.39(0.04-3.79)$ & 0.462 & $1.17(0.97-1.43)$ & 0.097 \\
\hline E7 & 9.3 & 7.8 & $1.22(0.60-2.47)$ & 0.603 & $1.06(0.97-1.15)$ & 0.182 \\
\hline L1 & 4.4 & 3.7 & $1.17(0.43-3.21)$ & 0.746 & $1.04(0.95-1.15)$ & 0.374 \\
\hline \multicolumn{7}{|l|}{ HPV 18} \\
\hline E6 & 1.6 & 1.4 & $1.18(0.23-5.93)$ & 0.877 & $1.02(0.93-1.13)$ & 0.632 \\
\hline E7 & 1.6 & 1.4 & $1.18(0.23-5.93)$ & 0.877 & $1.06(0.93-1.21)$ & 0.404 \\
\hline L1 & 0.5 & 1.8 & $0.29(0.03-2.66)$ & 0.229 & $1.00(0.91-1.11)$ & 0.948 \\
\hline \multicolumn{7}{|c|}{ Other high-risk HPV } \\
\hline 31 L1 & 6.6 & 8.8 & $0.72(0.34-1.53)$ & 0.402 & $1.00(0.92-1.09)$ & 0.988 \\
\hline 33 L1 & 0.5 & 0.5 & $1.23(0.08-20.03)$ & 0.887 & $1.03(0.93-1.15)$ & 0.537 \\
\hline 52 L1 & 34.4 & 33.6 & $1.04(0.68-1.57)$ & 0.883 & $1.00(0.90-1.11)$ & 0.989 \\
\hline $58 \mathrm{~L} 1$ & 13.7 & 12.0 & $1.17(0.65-2.10)$ & 0.611 & $1.03(0.94-1.12)$ & 0.543 \\
\hline \multicolumn{7}{|c|}{ Low-risk HPV } \\
\hline $6 \mathrm{~L} 1$ & 45.4 & 38.2 & $1.34(0.89-2.00)$ & 0.167 & $1.03(0.95-1.11)$ & 0.503 \\
\hline $11 \mathrm{~L} 1$ & 20.2 & 13.8 & $1.58(0.93-2.68)$ & 0.097 & $1.05(0.97-1.14)$ & 0.229 \\
\hline
\end{tabular}

a Seropositivity defined as $>400 \mathrm{MFI}$ (median fluorescence intensity)

${ }^{\mathrm{b}}$ The trend tests estimate the odds ratio for a one unit increase in natural log transformed MFI, adjusted for matched variables

c Nominal (uncorrected) $95 \%$ confidence intervals

${ }^{\mathrm{d}} P$-values are corrected for multiple comparisons using permutation tests

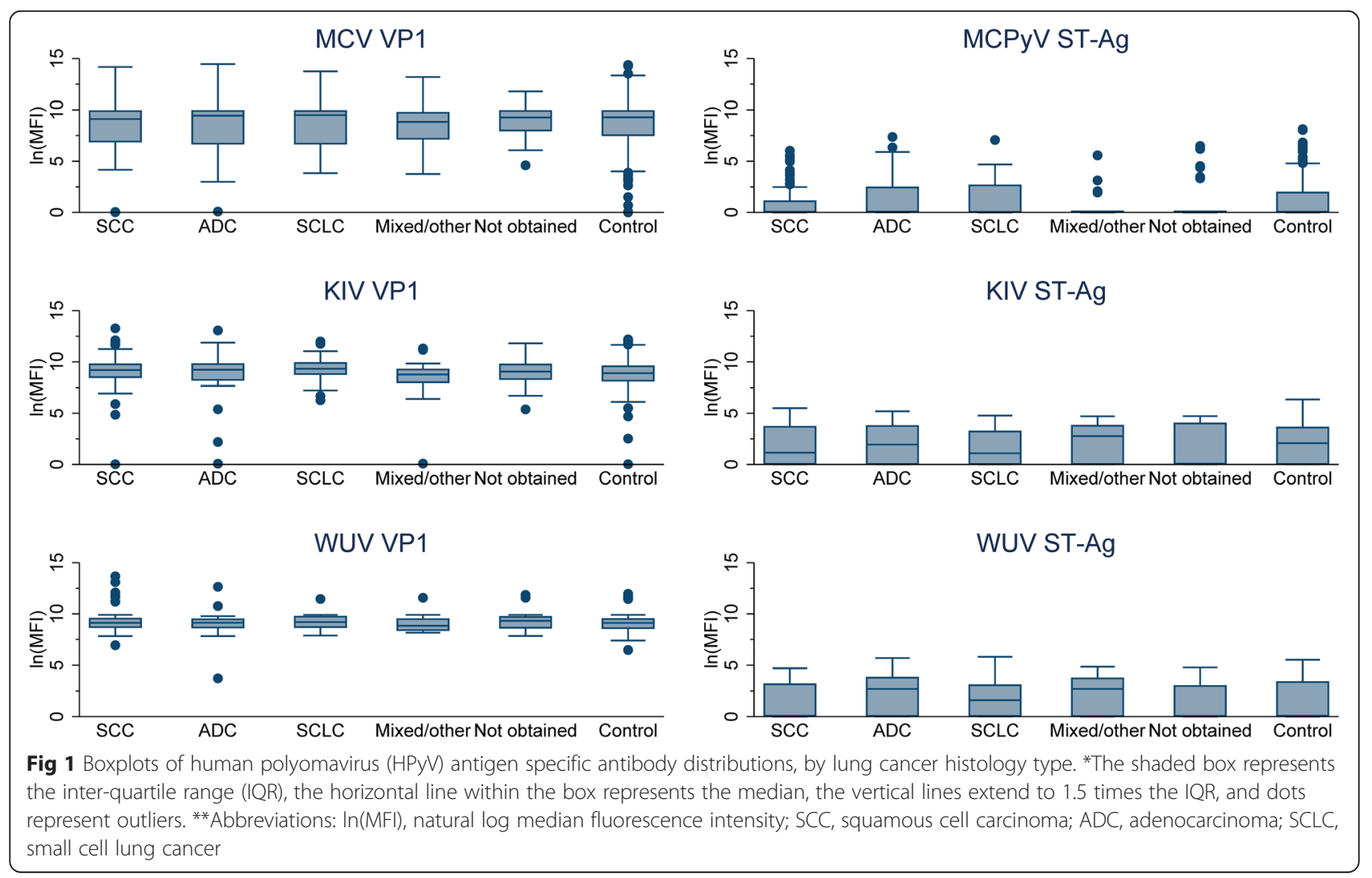



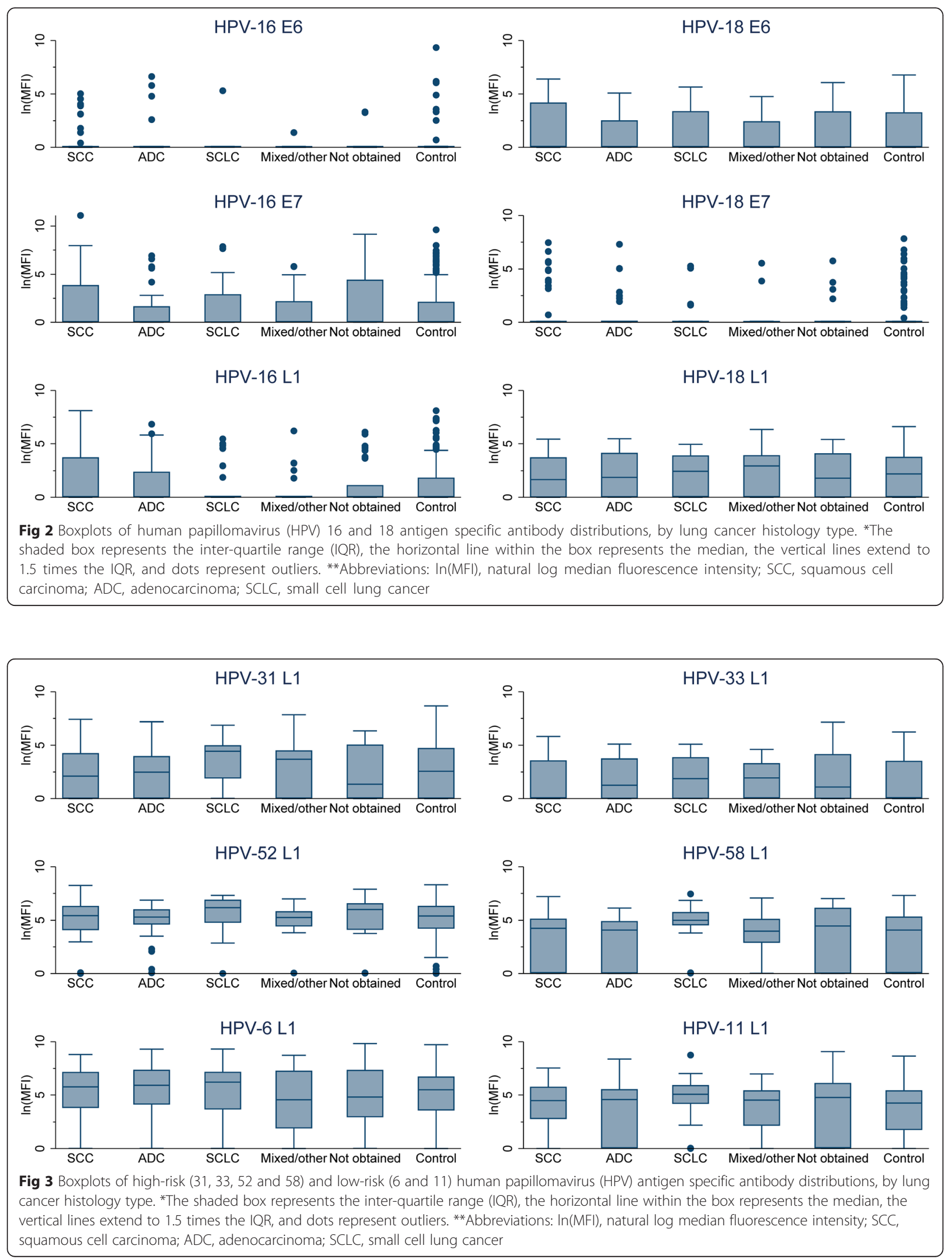
or whether negative associations were due to differences in selected primers $[26,27]$ and the use of formalinfixed paraffin embedded specimens, which may hinder attempts to amplify longer DNA segments [27, 40].

After completing the study and analyzing the data, we found that ever smoking status and level of education were associated with case/control status. Both factors could have potentially confounded the relationship between viral infection and lung cancer. While we were unable perform the analysis anew with matching on smoking history and education, we were able to assess confounding by including these factors as adjustment variables in sensitivity analyses. Since inclusion of these variables in the models did not substantially change the interpretation of our results, we reported the analysis adjusted for matching variables as our primary findings.

The primary limitation of this study is that all cohort members were at high risk for lung cancer due to occupational exposures. In the absence of interactive effects, these potent risk factors may obscure weaker contributions to lung cancer risk that might be observed in a broader population sample. This was by design, since we originally hypothesized that both HPVs and HPyVs might have an interactive effect with known carcinogens to contribute to lung cancer risk [41-43]. In addition, the study was underpowered for the examination of these associations by histologic type. However, some HPV types have been reported to be strongly associated with squamous cell carcinoma [28] and Merkel cell carcinoma is histologically similar to small cell carcinoma [44], so there may not have been an ideal distribution of histologic types for this study. The lack of specificity regarding the location of infection is also a limitation of our design. However, based on the limited number of seropositive samples, this is unlikely to have been important in this analysis. We also acknowledge that serology is not a gold standard for the evaluation of carcinogenic viruses associated with solid cancers [45]. Nevertheless, seroepidemiologic methods allow for ready selection of appropriate controls and are uniquely positioned to detect evidence for hit-and-run viral oncogenesis [46]. Finally, as mentioned above, another limitation is the potential lack of assay sensitivity compared to NAATs. The primary strengths of this study are the reduced susceptibility to contamination compared to NAATs and the temporal element that would have better informed causal inference if we did observe an association.

\section{Conclusions}

In summary, we found no association between KIV, WUV, and MCV antibody levels or HPV-16, 18, 31, 33, 52 , and 58 seropositivity and incident lung cancer in a high-risk male Asian cohort. Future studies of infectious etiologies of lung cancer should look beyond HPyVs and HPVs as candidate infectious agents.

\section{Additional files}

Additional file 1: Table S1. Association between antigen specific human polyomavirus (HPyV) antibody levels and incident lung cancer, adjusted for matching variables, ever smoking, and years of education. (DOCX $15 \mathrm{~kb}$ )

Additional file 2: Table S2. Association between human papillomavirus (HPV) seropositivity ${ }^{\mathrm{a}}$ and incident lung cancer, adjusted for matching variables. (DOCX $26 \mathrm{~kb}$ )

Additional file 3: Table S3. Association between human papillomavirus (HPV) seropositivity ${ }^{a}$ and incident lung cancer, adjusted for matching variables, ever smoking, and years of education. (DOCX $14 \mathrm{~kb}$ )

Additional file 4: Table S4. Association between human papillomavirus (HPV) seropositivity (alternate threshold) and incident lung cancer, adjusted for matching variables, ever smoking, and years of education. (DOCX $26 \mathrm{~kb})$

\section{Abbreviations}

$\mathrm{Cl}$, confidence interval; HPV, human papillomavirus; HPyV, human polyomavirus; KIV, KI polyomavirus; LBMA, liquid bead microarray; MFI, median fluorescent intensity; NAAT, nucleic acid amplification test; NCl, National Cancer Institute; ST-Ag, small T antigen; WUV, WU polyomavirus; YTC, Yunnan Tin Corporation

\section{Acknowledgements}

We extend our gratitude to the study participants, clinicians, and YTC personnel who made this study possible. We also thank and acknowledge the contributions of Greg Wipf for assistance in the laboratory, Ya-Guang Fan for translation and study facilitation, Yong Jiang for data preparation, and Margaret M. Madeleine, Lisa Johnson, and Alexa Resler for their consultation regarding study design and analytical methods.

\section{Funding}

This work was supported by the Fogarty International Clinical Research Scholars and Fellows Program at Vanderbilt University [R24 TW007988 trainee support to DVC]; the National Cancer Institute [R25 CA094880 trainee support to DVC]; the Intramural Research Program of the $\mathrm{NIH}$, the National Cancer Institute, and the Division of Cancer Epidemiology and Genetics; and the generous support of many individuals through Experiement.com. The funders had no role in study design, data collection and analysis, decision to publish, or preparation of the manuscript.

\section{Availability of data and materials}

The dataset supporting the conclusions of this article will be made available upon request. This study involved human subjects and to protect the privacy of study participants, data requests will be reviewed by the NCI DCEG Data Repository Committee. Requests should be directed to

NCIDCEGDataAccessRequests@mail.nih.gov.

\section{Authors' contributions}

DVC, LEM, JJC, SEH, NSW, Y-LQ, PRT, JSS, and DAG contributed to the conceptualization and design of this study. Y-LQ and PRT were involved in the acquisition of data and specimens. DVC and JJC conducted the experiments. DVC, LEM, JJC, SHE, NSW, JPH, JSS and DAG were involved in the analysis and interpretation of data. DVC drafted the manuscript and all authors were involved in revising it critically, and read and approved the final manuscript.

\section{Competing interests}

The authors of this manuscript have the following competing interests: Jennifer S. Smith has received unrestricted educational grants, consultancy, and research grants from GlaxoSmithKline and Merck Corporation over the past 5 years. You-Lin Qiao has received unrestricted educational grants, consultancy, and research grants from Qiagen, GlaxoSmithKline and Merck Corporation over the past 5 years. All other authors report no potential conflicts.

Consent for publication

Not applicable. 


\section{Ethics approval and consent to participate}

Participants provided signed informed consent and the institutional review boards (IRBs) of the National Cancer Institute (NCI) and the YTC approved the original cohort study. The IRBs of the University of Washington, the Fred Hutchinson Cancer Research Center, the Cancer Institute of the Chinese Academy of Medical Sciences, and the $\mathrm{NCl}$ approved this analysis.

\section{Author details}

'Department of Epidemiology, School of Public Health, University of Washington, Seattle, WA, USA. ${ }^{2}$ Fred Hutchinson Cancer Research Center, Seattle, WA, USA. ${ }^{3}$ Department of Biostatistics, School of Public Health, University of Washington, Seattle, WA, USA. ${ }^{4}$ Department of Cancer Epidemiology, Cancer Institute, Chinese Academy of Medical Sciences, Beijing, China. ${ }^{5}$ Genetic Epidemiology Branch, Division of Cancer Epidemiology and Genetics, National Cancer Institute, Bethesda, USA. ${ }^{6}$ Department of Epidemiology, Gillings School of Global Public Health, University of North Carolina, Chapel Hill, NC, USA. ${ }^{7}$ Institute for Health Metrics and Evaluation, University of Washington, 2301 5th Avenue, Suite 600, Seattle, WA 98121, USA.

Received: 8 January 2016 Accepted: 24 May 2016

\section{Published online: 01 June 2016}

\section{References}

1. Chen W, Zheng R, Zhang S, Zhao P, Zeng H, Zou X, He J. Annual report on status of cancer in China, 2010. Chin J Cancer Res. 2014;26:48-58.

2. GBD Compare. http://vizhub.healthdata.org/gbd-compare/. Accessed 15 May 2015.

3. She J, Yang P, Hong Q, Bai C. Lung cancer in China: Challenges and interventions. Chest. 2013;143:1117-26.

4. Lubin JH, Wang ZY, Boice JD, Xu ZY, Blot WJ, De Wang L, Kleinerman RA. Risk of lung cancer and residential radon in China: Pooled results of two studies. Int J Cancer. 2004;109:132-7.

5. Moore PS, Chang Y. Why do viruses cause cancer? Highlights of the first century of human tumour virology. Nat Rev Cancer. 2010;10:878-89.

6. Mesri E a, Feitelson M a, Munger K. Human viral oncogenesis: A cancer hallmarks analysis. Cell Host Microbe. 2014;15:266-82.

7. Feng H, Shuda M, Chang Y, Moore PS. Clonal integration of a polyomavirus in human Merkel cell carcinoma. Science. 2008;319:1096-100.

8. Babakir-Mina M, Ciccozzi M, Lo Presti A, Greco F, Perno CF, Ciotti M. Identification of Merkel cell polyomavirus in the lower respiratory tract of Italian patients. J Med Virol. 2010;82:505-9.

9. Allander T, Andreasson K, Gupta S, Bjerkner A, Bogdanovic G, Persson MAA, Dalianis T, Ramqvist T, Andersson B. Identification of a third human polyomavirus. J Virol. 2007:81:4130-6.

10. Gaynor AM, Nissen MD, Whiley DM, Mackay IM, Lambert SB, Wu G, Brennan DC, Storch G a, Sloots TP, Wang D. Identification of a novel polyomavirus from patients with acute respiratory tract infections. PLoS Pathog. 2007;3: e64.

11. Helmbold P, Lahtz C, Herpel E, Schnabel PA, Dammann RH. Frequent hypermethylation of RASSF1A tumour suppressor gene promoter and presence of Merkel cell polyomavirus in small cell lung cancer. Eur J Cancer. 2009;45:2207-11.

12. Joh J, Jenson a B, Moore GD, Rezazedeh A, Slone SP, Ghim S, Kloecker GH. Human papillomavirus (HPV) and Merkel cell polyomavirus (MCPyV) in non small cell lung cancer. Exp Mol Pathol. 2010;89:222-6.

13. Gheit T, Muñoz JP, Levican J, González C, Ampuero S, Parra B, Gaggero A, Corvalán AH, Meneses $M$, Tommasino $M$, Aguayo F. Merkel cell polyomavirus in non-small cell lung carcinomas from Chile. Exp Mol Pathol. 2012;93:162-6.

14. Hashida Y, Imajoh M, Nemoto Y, Kamioka M, Taniguchi A, Taguchi T, Kume M, Orihashi K, Daibata M. Detection of Merkel cell polyomavirus with a tumour-specific signature in non-small cell lung cancer. Br J Cancer. 2013; 108:629-37.

15. Babakir-Mina M, Ciccozzi M, Campitelli L, Aquaro S, Lo Coco A, Perno CF, Ciotti M. Identification of the novel KI Polyomavirus in paranasal and lung tissues. J Med Virol. 2009;81:558-61.

16. Duncavage EJ, Le B, Wang D, Pfeifer JD. Merkel cell polyomavirus: a specific marker for Merkel cell carcinoma in histologically similar tumors. Am J Surg Pathol. 2009;33:1771-7.
17. Teramoto S, Kaiho M, Takano Y, Endo R, Kikuta H, Sawa H, Ariga T, Ishiguro N. Detection of KI polyomavirus and WU polyomavirus DNA by real-time polymerase chain reaction in nasopharyngeal swabs and in normal lung and lung adenocarcinoma tissues. Microbiol Immunol. 2011;55:525-30.

18. Schmitt M, Höfler D, Koleganova N, Pawlita M. Human polyomaviruses and other human viruses in neuroendocrine tumors. Cancer Epidemiol Biomarkers Prev. 2011;20:1558-61.

19. Tolstov YL, Pastrana DV, Feng H, Becker JC, Jenkins FJ, Moschos S, Chang Y, Buck CB, Moore PS. Human Merkel cell polyomavirus infection II. MCV is a common human infection that can be detected by conformational capsid epitope immunoassays. Int J Cancer. 2009;125:1250-6.

20. Carter JJ, Paulson KG, Wipf GC, Miranda D, Madeleine MM, Johnson LG, Lemos BD, Lee S, Warcola AH, lyer JG, Nghiem P, Galloway DA. Association of Merkel cell polyomavirus-specific antibodies with Merkel cell carcinoma. J Natl Cancer Inst. 2009:101:1510-22.

21. Colombara DV, Manhart LE, Carter JJ, Hawes SE, Weiss NS, Hughes JP, Barnett MJ, Goodman GE, Smith JS, Qiao Y-L, Galloway DA. Prior human polyomavirus and papillomavirus infection and incident lung cancer: a nested case-control study. Cancer Causes Control. 2015;26:1835-44.

22. Grulich $A E$, Jin F, Conway EL, Stein AN, Hocking J. Cancers attributable to human papillomavirus infection. Sex Health. 2010;7:244-52.

23. Crosbie EJ, Einstein MH, Franceschi S, Kitchener HC. Human papillomavirus and cervical cancer. Lancet. 2013;6736.

24. Yuan H, Myers S, Wang J, Zhou D, Woo JA, Kallakury B, Ju A, Bazylewicz M, Carter YM, Albanese C, Grant N, Shad A, Dritschilo A, Liu X, Schlegel R. Use of Reprogrammed Cells to Identify Therapy for Respiratory Papillomatosis. N Engl J Med. 2012;367:1220-7.

25. DiLorenzo TP, Tamsen A, Abramson AL, Steinberg BM. Human papillomavirus type 6a DNA in the lung carcinoma of a patient with recurrent laryngeal papillomatosis is characterized by a partial duplication. J Gen Virol. 1992;73(Pt 2):423-8.

26. Klein F, Amin Kotb WFM, Petersen I. Incidence of human papilloma virus in lung cancer. Lung Cancer. 2009;65:13-8.

27. Srinivasan M, Taioli E, Ragin CC. Human papillomavirus type 16 and 18 in primary lung cancers-a meta-analysis. Carcinogenesis. 2009;30:1722-8

28. Zhai K, Ding J, Shi H. HPV and lung cancer risk: A meta-analysis. J Clin Virol. 2015;63:84-90.

29. Vanner EA., Shroyer KR. Comments on "HPV and lung cancer risk: A metaanalysis" [Zhai et al., J. Clin. Virol. (in press)]. J Clin Virol. 2015; 63(November 2014):91.

30. Qiao YL, Taylor PR, Yao SX, Erozan YS, Luo XC, Barrett MJ, Yan QY, Giffen C a, Huang SQ, Maher MM, Forman MR, Tockman MS. Risk factors and early detection of lung cancer in a cohort of Chinese tin miners. Ann Epidemiol. 1997;7:533-41.

31. Waterboer T, Sehr P, Michael KM, Franceschi S, Nieland JD, Joos TO, Templin MF, Pawlita M. Multiplex human papillomavirus serology based on in situ-purified glutathione s-transferase fusion proteins. Clin Chem. 2005;51:1845-53.

32. Waterboer T, Sehr P, Pawlita M. Suppression of non-specific binding in serological Luminex assays. J Immunol Methods. 2006;309:200-4.

33. Burnett-Hartman AN, Newcomb PA, Schwartz SM, Bostick RM, Pawlita M, Waterboer T, Potter JD. No association between antibodies to sexually transmitted infections and colorectal hyperplastic polyps in men: Minnesota Cancer Prevention Research Unit Polyp Study. Cancer Epidemiol Biomarkers Prev. 2012;21:1599-601.

34. Syrjänen $S$, Waterboer T, Sarkola M, Michael K, Rintala M, Syrjänen K, Grenman S, Pawlita M. Dynamics of human papillomavirus serology in women followed up for 36 months after pregnancy. J Gen Virol. 2009;90(Pt 6):1515-26.

35. Michael KM, Waterboer $T$, Sehr $P$, Rother A, Reidel U, Boeing $H$, Bravo IG, Schlehofer J, Gärtner BC, Pawlita M. Seroprevalence of 34 human papillomavirus types in the German general population. PLoS Pathog. 2008; 4, e1000091.

36. Ernst MD. Permutation Methods: A Basis for Exact Inference. Stat Sci. 2004;19:676-85.

37. Syriänen K. Detection of human papillomavirus in lung cancer: systematic review and meta-analysis. Anticancer Res. 2012;32:3235-50.

38. Anantharaman D, Gheit T, Waterboer T, Halec G, Carreira C, Abedi-Ardekani B, McKay-Chopin S, Zaridze D, Mukeria A, Szeszenia-Dabrowska N, Lissowska 
J, Mates D, Janout V, Foretova L, Bencko V, Rudnai P, Fabianova E, Tjønneland A, Travis RC, Boeing H, Quirós JR, Johansson M, Krogh V, Buenode-Mesquita HB, Kotanidou A, Clavel-Chapelon F, Weiderpass E, Johansson M, Pawlita M, Scelo G, et al. No causal association identified for human papillomavirus infections in lung cancer. Cancer Res. 2014;74:3525-34.

39. Koshiol J, Rotunno M, Gillison ML, Van Doorn L-J, Chaturvedi AK, Tarantini L, Song H, Quint WGV, Struijk L, Goldstein AM, Hildesheim A, Taylor PR, Wacholder S, Bertazzi PA, Landi MT, Caporaso NE. Assessment of human papillomavirus in lung tumor tissue. J Natl Cancer Inst. 2011;103:501-7.

40. Gilbert MTP, Haselkorn T, Bunce M, Sanchez JJ, Lucas SB, Jewell LD, Van Marck E, Worobey M. The isolation of nucleic acids from fixed, paraffinembedded tissues-which methods are useful when? PLoS One. 2007;2, e537.

41. Mogha A, Fautrel A, Mouchet N, Guo N, Corre S, Adamski H, Watier E, Misery L, Galibert M-D. Merkel cell polyomavirus small T antigen mRNA level is increased following in vivo UV-radiation. PLoS One. 2010;5, e11423.

42. Bohlmeyer T, Le TN, Shroyer AL, Markham N, Shroyer KR. Detection of human papillomavirus in squamous cell carcinomas of the lung by polymerase chain reaction. Am J Respir Cell Mol Biol. 1998;18:265-9.

43. Syrjänen KJ. HPV infections and lung cancer. J Clin Pathol. 2002;55:885-91.

44. Leech SN, Kolar a J, Barrett PD, Sinclair S a, Leonard N. Merkel cell carcinoma can be distinguished from metastatic small cell carcinoma using antibodies to cytokeratin 20 and thyroid transcription factor 1. J Clin Pathol. 2001;54:727-9.

45. De Paoli P, Carbone A. Carcinogenic viruses and solid cancers without sufficient evidence of causal association. Int J Cancer. 2013;133:1517-29.

46. Ambinder RF. Gammaherpesviruses and "Hit-and-Run" oncogenesis. Am J Pathol. 2000:156:1-3.

\section{Submit your next manuscript to BioMed Central and we will help you at every step:}

- We accept pre-submission inquiries

- Our selector tool helps you to find the most relevant journal

- We provide round the clock customer support

- Convenient online submission

- Thorough peer review

- Inclusion in PubMed and all major indexing services

- Maximum visibility for your research

Submit your manuscript at www.biomedcentral.com/submit 